\title{
A multidisciplinary approach in the diagnostic challenge of GIST
}

\author{
MIHAI CEAUSU ${ }^{1}$, BOGDAN SOCEA ${ }^{2,3}$, VLADIMIR PAUL CIOBOTARU ${ }^{2,3}$, VLAD DENIS CONSTANTIN ${ }^{2,3}$, \\ SIMONA ENACHE ${ }^{4}$, VALENTIN ENACHE ${ }^{4}$, ALICE BANCU ${ }^{5}$, LAURA ILEANA SOCEA ${ }^{6}$, DRAGOȘ ȘERBAN ${ }^{2,7}$, \\ DRAGOȘ PREDESCU ${ }^{2,8}$, CĂTĂLIN G. SMARANDACHE ${ }^{2,7}$ and ZENAIDA CEAUSU ${ }^{9}$
}

\author{
Departments of ${ }^{1}$ Pathology and ${ }^{2}$ Surgery, 'Carol Davila' University of Medicine and Pharmacy, 020021 Bucharest; \\ ${ }^{3}$ Department of Surgery, 'Sf. Pantelimon' Emergency Clinical Hospital, 021659 Bucharest; ${ }^{4}$ Pathology Department, \\ University Emergency Hospital, 050098 Bucharest; ${ }^{5}$ Pathology Department, 'Victor Babeş' Institute of Bucharest, \\ 050096 Bucharest; ${ }^{6}$ Department of Organic Chemistry, Faculty of Pharmacy, 'Carol Davila' University of \\ Medicine and Pharmacy, 020956 Bucharest; ${ }^{7}$ Department of Surgery, University Emergency Hospital, \\ 050098 Bucharest; ${ }^{8}$ Department of Surgery, 'Sf. Maria' Hospital, 011172 Bucharest; ${ }^{9}$ Pathology Department, \\ ‘Sf. Pantelimon’ Emergency Hospital, 021659 Bucharest, Romania
}

Received May 31, 2021; Accepted June 30, 2021

DOI: $10.3892 / \mathrm{etm} .2021 .10497$

\begin{abstract}
Gastrointestinal stromal tumors (GISTs) are the most common malignant mesenchymal lesions of the gastrointestinal tract. They originate from the interstitial cells of Cajal and are characterized by overexpression of the tyrosine kinase receptor, protein product of c-KIT gene (KIT). In this retrospective study, conducted over a period of 10 years, we retrieved from our database, a total number of 57 patients, admitted and operated in the surgical department of 'Sf. Pantelimon' Emergency Clinical Hospital, Bucharest, for digestive tumors, histopathologically confirmed as GISTs. More than half of the cases presented as surgical emergencies and the tumors found during the surgical procedures, which proved to be GISTs, were sometimes difficult to differentiate from other mesenchymal tumors, both for the clinician and the pathologist. The diagnosis of GIST relies mostly on pathology and immunohistochemistry, but also on clinical and imagistic data. The most common emergencies were digestive hemorrhage (associated with gastric location), followed by intestinal obstruction (especially for the ileal localization). The largest dimensions corresponded to gastric location. For selected indications (upper digestive sites), upper digestive endoscopy approaches $100 \%$ sensitivity. This study focuses on diagnosis of GISTs sustained by both clinical and imagistic methods, along with histopathology and immunohistochemistry techniques, according to the World Health Organization 2019 criteria. Even though the differential diagnosis of these tumors
\end{abstract}

Correspondence to: Dr Bogdan Socea, Department of Surgery, 'Carol Davila' University of Medicine and Pharmacy, 37 Dionisie Lupu Street, 020021 Bucharest, Romania

E-mail: bogdan.socea@umfcd.ro

Key words: GIST, stromal tumors, diagnosis, CT-scan, immunohistochemistry is challenging, an interdisciplinary cooperation with a multiple approach increases the odds of a correct positive diagnosis.

\section{Introduction}

Although gastrointestinal stromal tumors (GISTs) are rare entities, they represent the most common mesenchymal tumors arising in the digestive tract. They show variable malignant potential and are thought to derive from the interstitial cells of Cajal. Their most frequent anatomical location is the stomach, followed by the jejunum, ileum, duodenum, colon and rectum (1). Extradigestive tumors have also been reported. However, most of them are found in close proximity to the gastrointestinal (GI) tract, such as in the omentum, mesentery, retroperitoneum or pleura (2). GISTs can occur at any age, but they are more prevalent in patients between 60 and 65 years of age. On the other hand, a subtype of GISTs usually affects younger patients and mostly women; these tumors are frequently succinate dehydrogenase (SDH)-deficient and preferentially involve the distal stomach and antrum. This type of GIST is called 'wild'-type GIST (3). GISTs are either sporadic or synchronous. The former represents a majority of cases. The latter are usually associated with SDH deficiency (as in Carney triad or Carney-Stratakis syndrome) (4). Carney triad is caused by non-hereditary succinate dehydrogenase complex subunit $\mathrm{C}(S D H C)$ hypermethylation and comprises gastric GISTs, extra-adrenal paragangliomas and pulmonary chondromas. Carney-Stratakis syndrome is characterized by gastric GISTs and paragangliomas. It is a rare heritable, autosomal-dominant condition, caused by a germline mutation of the SDH complex. Abnormalities may be located in the SDHB, C or D subunits (5). SDH-deficient GISTs usually occur in young patients, are associated with more frequent lymph vessel invasion and frequently metastasize to lymph nodes, in addition to the liver and peritoneum. They are associated with an indolent course, despite their metastatic spread (6).

Whenever possible, surgical resection is recommended. Histopathological examination (resection specimen or biopsy), 
along with immunohistochemistry, are mandatory for the positive and differential diagnosis of GISTs. Targeted drug therapy with imatinib for a long term is recommended postoperatively in almost all cases (7).

\section{Materials and methods}

Case selection for human tissue specimens of the study batch. A retrospective study was performed on a study batch composed of 57 cases with GISTs, selected during an interval of 10 years (January 1, 2011 to December 31, 2020). The patients were admitted to the Department of Surgery, 'Sf. Pantelimon' Emergency Clinical Hospital, Bucharest, Romania, where surgical procedures were performed. The study batch consisted of 37 male and 20 female patients (sex ratio male:female $=1.85 / 1$ ), with ages ranging between 46 and 82 years (mean age: 68.31 years, standard deviation $\mathrm{SD} \pm 7.62$ ) (Table I).

The study was performed according to the 1975 World Medical Association Declaration of Helsinki ethical guidelines, as amended in Brazil, in 2013. The tissue specimens were collected according to national legislation, using a protocol approved by the local bioethics committees. All the patients included in the study previously signed the hospital's standard informed consent at their admission, regarding medical procedures, tissue sampling and possible future publication of their data. The local ethical committee of 'Sf. Pantelimon' Emergency Clinical Hospital, Bucharest review the protocol and provide formal approval (IRB no. 7/05.01.2021).

The inclusion criteria were as follows: i) All patients were adults ( $>18$ years of age); ii) all patients were admitted to the surgical department in the designated period of time; iii) all patients had a surgical procedure with tissue sampling; and iv) all patients had a histopathology confirmation of GIST, including immunohistochemistry.

The exclusion criteria were, as follows. We excluded all the patient with digestive tumors, although suggestive for GIST, but who had not undergone a surgical procedure and who had no histopathological confirmation of GIST, including immunohistochemistry. Thus, we excluded all the cases for whom the tumors could not be confirmed as GISTs with no doubts, as the differential diagnosis was not very clear even after immunohistochemistry investigations were conducted.

All data were retrieved from a single surgical center.

According to the latest World Health Organization (WHO) classification (2019) $(8,9)$, we took into account the essential diagnostic criteria along with desirable diagnostic criteria documented for GISTs. The essential criteria included: An intramural, submucosal or subserosal mass, spindle-cell, epithelioid or mixed cell morphology, protein product of c-KIT (KIT) gene and/or discovered on GIST (DOG1) immunopositivity and SDHB loss in SDH-deficient GISTs. The desirable criteria are KIT or platelet-derived growth factor receptor $\alpha$ (PDGFRA) gene mutations in approximately $85 \%$ of tumors. In addition, the prognostic parameters for GISTs are mitotic activity, tumor size and anatomical site $(8,9)$.

The objective of the study was to assess, for the patients included, the fulfillment of the diagnostic criteria according to WHO 2019 classification.
Clinical and imagistic investigation. Table II documents the preoperative investigations performed for the patients included in the study: Abdominal ultrasound, contrast computed tomography (CT) scan, upper endoscopy, and lower endoscopy (recto-colonoscopy). We considered as positive the results that detected a tumor mass located on the digestive tract (sensitivity).

It can be noted that the upper digestive endoscopy was useful in diagnosing all submucosal tumors with esophageal, gastric and duodenal location. Therefore, we concluded that for these locations, the sensitivity was $100 \%$. Overall, considering all investigations, regardless of localization, CT scan (Fig. 1) was found to be significantly more sensitive than the others $(\mathrm{P}=0.025)$. Abdominal ultrasound, even with a lower sensitivity, has definite cost advantages, lack of irradiation and reproducibility (Fig. 2).

All patients underwent surgery, benefiting from resection of the tumor, or a segment of the digestive tract that included the tumor. The operation was performed under conditions of immediate emergency in 5 cases (hemorrhage, peritonitis), delayed emergency in 27 cases and electively in 25 cases, by classical (46 cases) or laparoscopic approach (11 cases). Sometimes, digestive GISTs can have impressive dimensions (Fig. 3).

Histopathologic investigation (tissue sampling and staining). Tissue specimens from surgically excised GISTs were taken for histopathologic investigations. The fragments were harvested from the esophagus, stomach, jejunum, ileum and sigmoid. The selected tissue samples were fixed in $10 \%$ neutral buffered formalin $(\mathrm{pH} 7.0)$ and paraffin embedded. Sections were cut at $5 \mu \mathrm{m}$ and stained (room temperature, 4-6 h) with standard hematoxylin and eosin (H\&E) and elastic van Gieson.

Immunohistochemical analysis (IHC) was performed for a panel of 7 antibodies, using sections displayed on slides treated first with poly-L-lysine. The panel consisted of the following antibodies: CD117 (clone: T 595, RTU, Novocastra), CD34 (clone: QBend, RTU, Novocastra), vimentin (clone: V9, RTU, Novocastra), smooth muscle actin (clone: 1a4, RTU, Abcam), S-100 (poly, RTU, Novocastra), DOG1 (clone: SP31, 1:100, Spring Bioscience), PDGFR- $\alpha$ (clone: C-20, 1:100, Santa Cruz Biotechnology, Inc.). IHC was performed on $3-\mu \mathrm{m}$ thick sections from formalin-fixed paraffin-embedded specimens.

The method used was an indirect tristadial Avidin-BiotinComplex technique, with a NovoLink Polymer detection system which utilizes a novel control polymerization technology to prepare polymeric HRP-linker antibody conjugates, according to the manufacturer's specifications (Novocastra). Antigen retrieval technique (enzymatic pre-treatment) was performed for some of the aforementioned antibodies, according to the producer's specifications.

The slides were examined and photographed on a Zeiss Axio Imager microscope (Zeiss) and the digital images acquired with Axio Vision program were processed and analyzed with an incorporated software program, running under Windows 10.

Statistical analysis. Statistical analysis was conducted using the Student's t-test, for mean, median and standard deviation. A value of $\mathrm{P}<0.05$ was considered statistically significant. 
Table I. General characteristics of the patients with GISTs included in the study.

\begin{tabular}{lc}
\hline Total cases & $\mathrm{N}=57$ \\
\hline Sex & \\
Male & 37 \\
Female & 20 \\
Age (years) (mean \pm SD) & $68.31 \pm 7.62$ \\
Minimum & 46 \\
Maximum & 82 \\
Tumoral dimension (cm) (mean \pm SD) & $4.64 \pm 2.02$ \\
Minimum & 2 \\
Maximum & 15 \\
Tumoral location, n (\%) & \\
Inferior esophagus & $1(1.75)$ \\
Gastric, anterior wall & $4(7.01)$ \\
Gastric, posterior wall & $8(14.03)$ \\
Gastric, lesser curvature & $5(8.77)$ \\
Gastric, greater curvature & $5(8.77)$ \\
Gastric, antrum or prepyloric & $6(10.52)$ \\
Duodenum & $1(1.75)$ \\
Jejunum & $11(19.29)$ \\
Ileum & $12(21.05)$ \\
Appendix & $1(1.75)$ \\
Descending colon & $1(1.75)$ \\
Sigmoid & $2(3.5)$ \\
\hline
\end{tabular}

GISTs, gastrointestinal stromal tumors.

Table II. Rate of positive findings in various investigations.

\begin{tabular}{lcc}
\hline & $\begin{array}{c}\text { No. of patients } \\
\text { (percent from total, } \\
\mathrm{n}=57)(\%)\end{array}$ & $\begin{array}{c}\text { Sensitivity } \\
(\%)\end{array}$ \\
\hline Anvestigation & $55(96.49)$ & $23(41.81)$ \\
CT scan & $39(68.42)$ & $33(84.61)$ \\
Upper endoscopy & $44(77.19)$ & $30(68.18)$ \\
Lower endoscopy & $7(12.28)$ & $2(28.57)$ \\
\hline
\end{tabular}

\section{Results}

We noted a quite uniform distribution of the cases over the 10 years of our study, without statistically significant differences, except for the year 2020, with only 3 cases, in the context of the COVID-19 pandemic (Fig. 4).

Gastric GISTs were recorded in 28 cases (49.12\%), jejunal GISTs in 11 cases (19.3\%) and ileal GISTs in 12 cases (21\%). Other locations were the sigmoid (2 cases), esophagus (1 case), duodenum ( 1 case), appendix ( 1 case) and colon ( 1 case). The mean tumor size was $4.64 \mathrm{~cm}(\mathrm{SD} \pm 2.02)$, ranging from 2 to $15 \mathrm{~cm}$ (Table I). The sizes of GISTs can be extremely variable, from tiny incidental cases to huge masses (10). Large

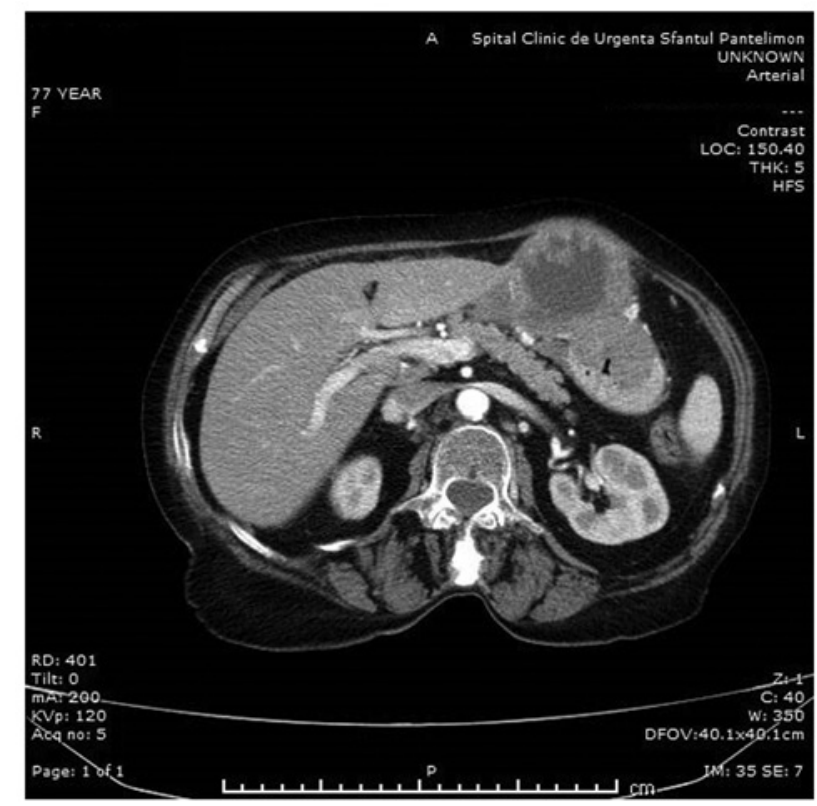

Figure 1. Axial image of a contrast CT scan for a gastric GIST (the tumor protruding through skin on the abdominal anterior left wall). CT, computed tomography; GIST, gastrointestinal stromal tumor.

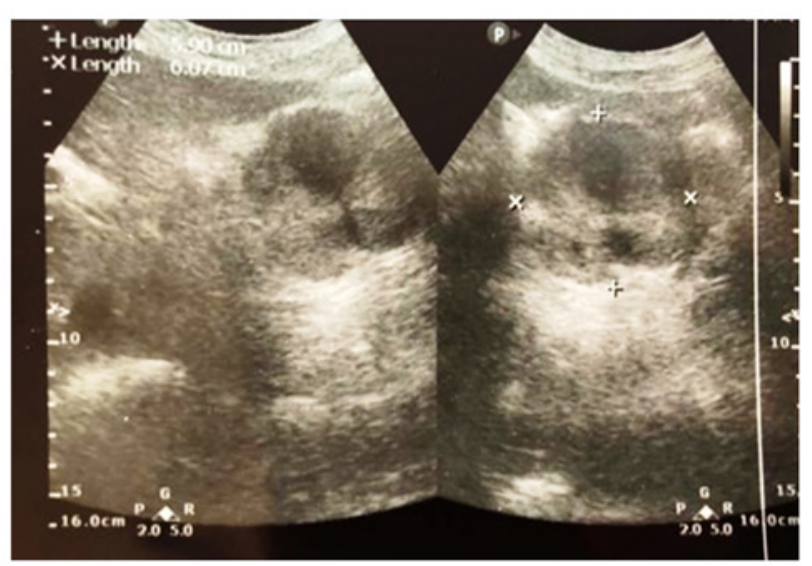

Figure 2. Transabdominal ultrasound image of a digestive GIST (dimensions $5.90 / 6.07 \mathrm{~cm})$. GIST, gastrointestinal stromal tumor.

GISTs almost always outgrow their vascular supply, leading to extensive areas of necrosis and hemorrhage $(11,12)$. The largest tumors encountered (15 $\mathrm{cm}$ in the longest axis) had gastric location. The average size of the tumors with gastric localization was significantly larger than those for other localizations (5.21 vs. $4.08 \mathrm{~cm} ; \mathrm{P}=0.047$ ).

Regarding the clinical presentation of patients, we noted the emergency presentation of over half of the patients (32 out of 57, which represents $56.14 \%$, a high proportion). We explained this large proportion of emergencies through the department's profile.

As shown in Table III, the most common emergency presentation in our study was digestive hemorrhage [12 cases (21.05\% of all patients)], concordant with data from literature (13), followed by intestinal obstruction [10 cases $(17.54 \%)$ ], the data being in accordance with our previous observations (14). 
Table III. Acute presentations of patients at admission.

\begin{tabular}{lcc}
\hline $\begin{array}{l}\text { Causes of complications } \\
\text { at admission }\end{array}$ & $\begin{array}{c}\text { No. of } \\
\text { patients }\end{array}$ & $\begin{array}{r}\text { Percent from } \\
\text { total }(\mathrm{n}=57)\end{array}$ \\
\hline Digestive hemorrhage & 12 & 21.05 \\
Intestinal obstruction & 10 & 17.54 \\
Spontaneous tumor perforation & 3 & 5.26 \\
with acute peritonitis & & \\
Pyloric stenosis & 2 & 3.50 \\
Cardial stenosis & 1 & 1.75 \\
Intussusception & 1 & 1.75 \\
Jaundice & 1 & 1.75 \\
Retroperitoneal invasion & 1 & 1.75 \\
Acute appendicitis & 1 & 1.75 \\
\hline
\end{tabular}

There was also one case (male, 55 years of age) who presented with acute appendicitis, which is a rare observation, to date, only 9 cases being previously mentioned in the literature (15). Two other types of acute presentations, rarely mentioned previously in the literature, were 3 cases $(5.26 \%)$ of spontaneous rupture of GIST with subsequent peritonitis (16), an ileal intussusception (female, 59 years) (17) and a case with retroperitoneal invasion $(18,19)$. Other peculiar complications included jaundice and pyloric or cardial stenosis (Table III).

Analyzing the data from the statistical point of view, we found a strong positive association between hemorrhage at presentation and gastric localization $(75 \%, \mathrm{P}=0.025)$ and, respectively, between intestinal occlusion and ileal localization $(60 \%, \mathrm{P}=0.045)$.

From the microscopic point of view, both spindle-shape cells and epithelioid cells were noted in the investigated GISTs. Spindle cells were arranged in foci of fascicles or short whorls, composed of cells with eosinophilic cytoplasm, bland elongated nuclei and rarely with paranuclear artifactual vacuoles (Fig. 5A). Epithelioid cells showed nests or sheets of polygonal to plump round cells with abundant eosinophilic to clear cytoplasm (Fig. 5B). A variable desmoplastic reaction, due to interstitial collagen deposition was noted both in GISTs with spindle-cells and GISTs with epithelioid cells.

CD117 stained positive, diffusely or focally, in tumor cells showing cytoplasmic or perinuclear dot reaction. The IHC reaction was observed in all cases, with various intensities, both in the spindle cell and epithelioid type of tumors (Fig. 6A and C). Mast cells were used as a positive internal control reaction. CD34 was positive in half of the cases, with moderate or strong cytoplasmic reaction in the tumor cells, in both types of tumors (with spindle-shape and epithelioid cells) (Fig. 6B and D).

Capillary vessels were used as positive internal control. DOG1 was found positive in the studied cases, in the cytoplasm of the tumor cells (Fig. 7A). PDGFR- $\alpha$ was positive in all cases, in the cytoplasm of the tumor cells, with variable intensity (Fig. 7B).

In some cases, tumor cells showed smooth muscle differentiation, staining positive for $\alpha$-smooth muscle actin ( $\alpha$-SMA ) or neural differentiation, staining positive for S-100

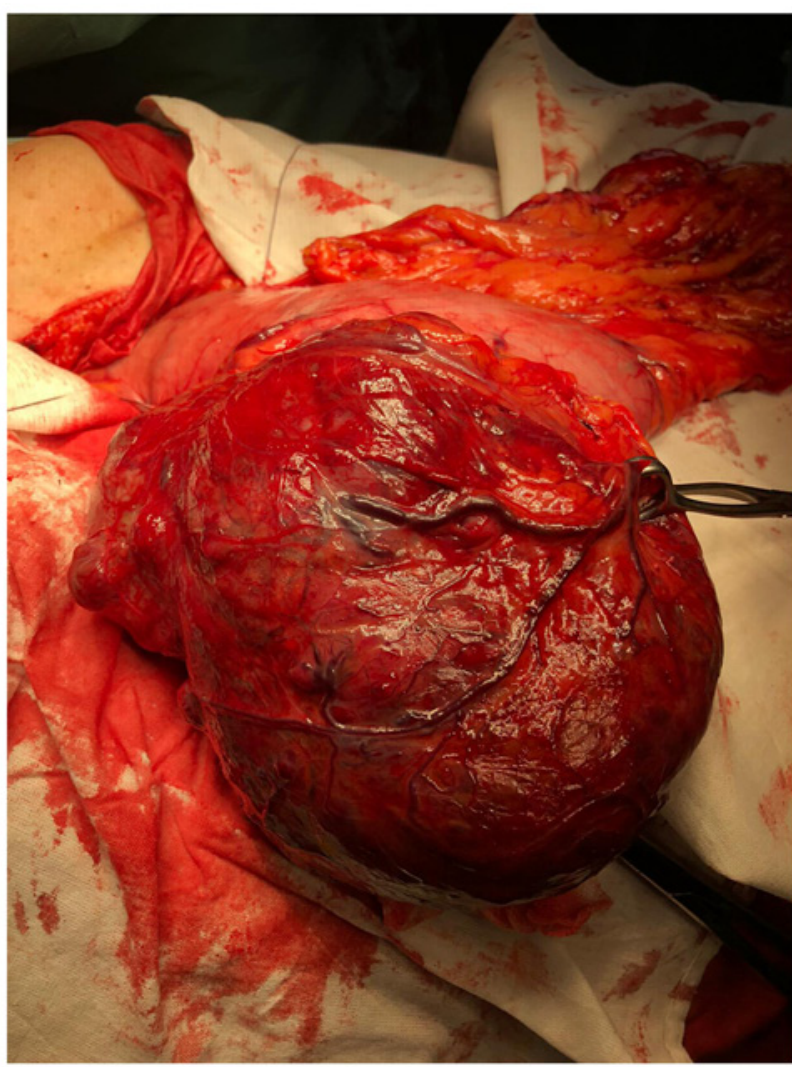

Figure 3. Intraoperative finding of a giant gastric GIST (open surgery). GIST, gastrointestinal stromal tumor.

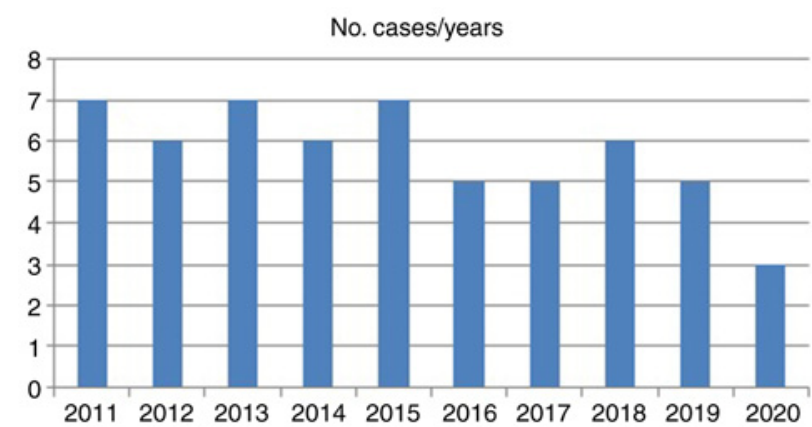

Figure 4. Distribution of cases by years (x-axis, year; $y$-axis, number of cases).

(Fig. 8A and B). The reaction was cytoplasmic with variable intensity. IHC for vimentin was mild or moderate in the cytoplasm of tumor cells.

\section{Discussion}

More than half of the GISTs in our study presented as surgical emergencies. The most common emergency was digestive hemorrhage (positively associated with gastric location), followed by intestinal obstruction (particularly for ileal localization). The largest dimensions were found for gastric GISTs. This fact was also observed by other authors (20). According to the latest WHO prognostic classification, dimension is an independent prognostic factor for anatomic location (8). In other research, malignant GISTs were associated with location in organs other than the stomach (21). 
A

B

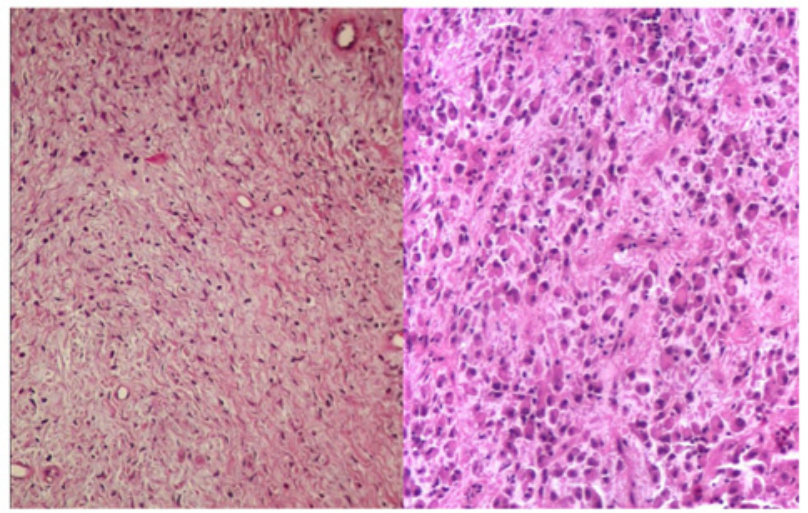

Figure 5. Microscopic appearance of GISTs (H\&E; magnification x100). (A) Elongated spindle-shape and star-shape cells embedded in a fibrous stroma in a GIST with spindle cells. (B) Solid sheets of plump cells with eosinophilic cytoplasm in a GIST with epithelioid cells. GIST, gastrointestinal stromal tumor; H\&E, hematoxylin and eosin.

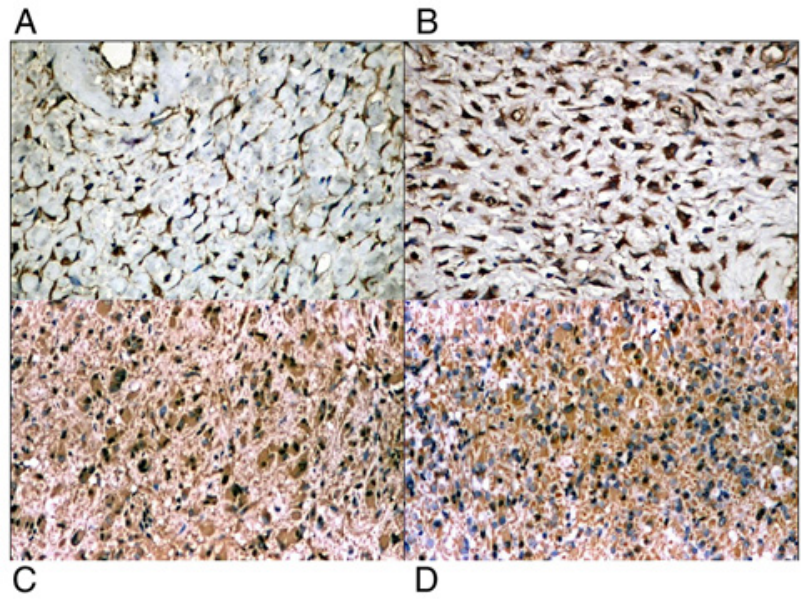

Figure 6. IHC reaction in GIST (IHC, magnification, x100). (A) CD117 positivity in spindle cells. (B) CD34 positivity in spindle cells. (C) CD117 positivity in epithelioid cells. (D) CD34 positivity in epithelioid cells. IHC, immunohistochemical; GIST, gastrointestinal stromal tumor.

The standard paraclinical examination is based on abdominal CT scan, which is considered the gold standard in the initial imaging of GISTs and in monitoring their therapeutic response (22), as it allows precise detection of the primary tumor, its local extent and metastases. In our study, 39 patients underwent preoperative contrast CT scan, which showed a sensitivity of $84.61 \%$. Standard ultrasonography is commonly used in the setting of liver metastases $(23,24)$. For the primary mass, ultrasound showed a low sensitivity $(41.81 \%)$. Magnetic resonance imaging (MRI) is useful not only in rectal and duodenal primary GISTs, but also in cases of liver metastases (25). In our study, there were only 5 preoperative cases who underwent MRI, so that we could not take them into consideration for analysis. Other useful investigation techniques include endoscopy and positron emission tomography (PET). Upper endoscopy showed a high sensitivity for tumors located in the upper digestive tract (esophagus, stomach, duodenum); $100 \%$ detection for submucosal masses in our study. PET is considered superior to CT alone in the imaging
A

B

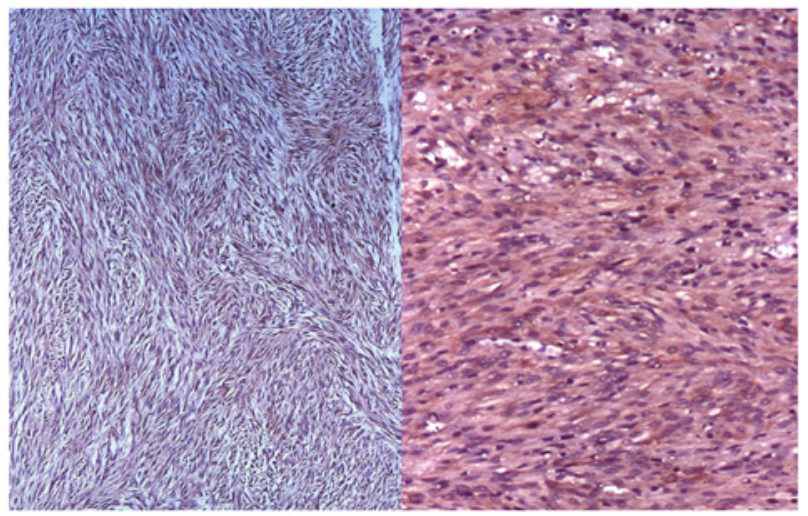

Figure 7. Immunohistochemical (IHC) reaction in GIST. (A) Left panel, DOG1 positivity in spindle cells (IHC, magnification x100). (B) PDGFR-o positivity in spindle cells (IHC, magnification, x200). GIST, gastrointestinal stromal tumor; DOG1, discovered on GIST; PDGFR- $\alpha$, platelet-derived growth factor receptor- $\alpha$.

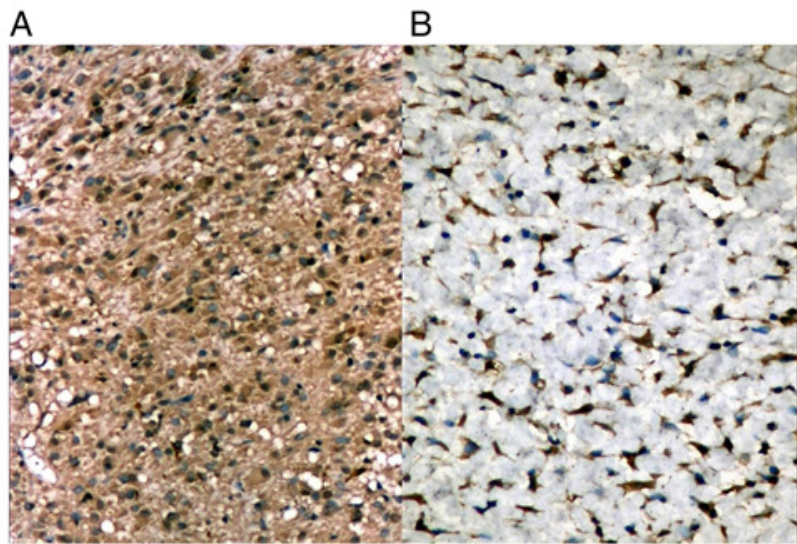

Figure 8. IHC reaction in GIST (IHC, magnification x100). (A) SMA positivity in epithelioid tumor cells. (B) S-100 positivity in spindle-shape cells. IHC, immunohistochemical; GIST, gastrointestinal stromal tumor; SMA, smooth muscle actin; S-100, protein S-100.

of liver metastases (26). We had no preoperative PET scan for the patients included. A preoperative biopsy is not generally recommended when there is a high index of suspicion for GIST and the lesion is resectable (27). We counted 11 mucosal biopsies for submucosal masses, endoscopically taken, that showed no malignant lesions. In cases of high suspicion of malignant GIST, biopsy is even prohibitive. The prognosis is worse for ruptured tumors and tumor biopsy can produce dissemination.

For selected indications (upper digestive sites), upper digestive endoscopy approached $100 \%$ sensitivity in our study, detecting submucosal masses, but biopsy is not useful since the mucosa remains normal. Overall, regardless of the location, CT scan was found to be the most sensitive investigation. The gastric tumors presented as intramural masses in most of the cases, while GISTs from the small bowel presented as subserosal extrinsic masses. Up to three quarters were spindle-cell GISTs and the tumor cells stained positive to KIT, DOG1 and PDGFR- $\alpha$ in all investigated cases, followed by CD34, which was positive in $50 \%$ of the cases. Molecular analysis was not performed, therefore gene mutations was not assessed. 
In the present study, all included patients fulfilled diagnostic criteria according to the recent WHO classification, from 2019, except that molecular analysis was not conducted (8).

Pathology examination had a major role, both in preoperative confirmation of diagnosis and after complete surgical excision. The diagnosis of GISTs relies on morphology and immunohistochemistry, and in certain cases on molecular analysis as complementary diagnosis (28). Gastric GISTs usually have an intramural and a luminal component. GISTs located in the small bowel are more frequently extrinsic masses. The cut surface is frequently whorled, fleshy, whitish-tan to pink. Areas of necrosis, hemorrhage and cyst formation can be seen in larger lesions (29). Gastric GISTs are composed of spindle cells in a majority of cases. Small and large intestine GISTs usually consist of spindle cells arranged in sheets or storiform-like patterns, but sometimes may have epithelioid cells. SDH-deficient tumors are often epithelioid and patients with SDH-deficient GISTs are younger than those with tyrosine kinase receptor gene mutant tumors (30). Extracellular acidophilic globules composed of collagen [skenoid periodic acid-Schiff (PAS)-positive fibers] may be observed and are usually associated with non-aggressive intestinal tumors (9).

Regarding immunohistochemistry, approximately $95 \%$ of the GISTs showed KIT positivity, which is considered a sensitive and specific marker for GISTs (31). DOG1 might contribute to a definitive diagnosis (up to half of all KIT-negative tumors show DOG1 positivity). This is frequently the case with PDGFRA-mutated tumors, which are usually positive for DOG1 and PDGFRA (32). CD34 is an early GIST marker, but it is less sensitive and specific than KIT and DOG1. The staining is variable (50-90\% of cases) and depends on anatomical location (33). GISTs may also show variable cytoplasmic staining to vimentin, SMA or desmin. Small intestine GISTs express more often S100 and SMA. SMA is also a negative prognostic factor in localized tumors (there is a direct correlation between its positivity and disease relapse) $(34,35)$.

The differential diagnosis is broad and includes both spindle cell and epithelioid mesenchymal tumors in origin (36). Considering this, the differential diagnosis should be made with leiomyomas and leiomyosarcomas [desmin is frequently positive in smooth muscle neoplasms, but SMA and caldesmon can be positive in all the three types (37)], intraabdominal desmoid fibromatoses [which have a characteristic nuclear immunopositivity for $\beta$-catenin and a weak expression for KIT (38)], inflammatory myofibroblastic tumors [which show desmin and SMA reactivity, while ALK-1 can be positive in a subset of cases (39)] and schwannomas of the GI tract [which show S100 and GFAP positivity (40)]. Other tumors that should be considered for the differential diagnosis are solitary fibrous tumors [which can stain positive to CD34, but they show STAT6 nuclear positivity and are negative for KIT and PDGFRA (41)], glomus tumors (which are almost always positive for SMA, but they are negative for KIT, DOG1 and CD34) and perivascular epithelioid cell tumors (PEComas) [which show no DOG1 staining, but they show simultaneous positivity for SMA, HMB45, Melan A (42)].

The main limitation of this study is represented by its retrospective nature, which may imply selection and indication biases, although that did not influence patient selection or management. The second limitation is the relatively small study population, partially related to the loss of several cases for non-operative procedures; despite that, we should keep in mind that our study focused on a highly selected subclass of patients from a single surgical center. Even if there was a limited number of cases, these cases were gathered in a period of 10 years. The third limitation is represented by the lack of molecular analysis.

In patients with clinical symptoms and imagistic data suggestive of a digestive tumor, the diagnosis of GIST should be considered, even though it is not a common tumor. A correct diagnosis is essential for appropriate treatment, with subsequent improvement of life quality. According to a correct and complete diagnostic, adjuvant prolonged treatment with imatinib (3 years after surgery or even longer) improves the outcome and prognosis (43). Risk stratification schemes are based on tumor size, mitosis count and site and assessment of rupture (43).

In conclusion, in our study, more than $50 \%$ of the GISTs presented as surgical emergencies. The most common emergency was digestive hemorrhage (associated with gastric location), followed by intestinal obstruction (particularly for ileal localization). The largest dimensions were found for gastric GISTs. For selected indications (upper digestive sites), upper digestive endoscopy approached $100 \%$ sensitivity. Overall, regardless of location, CT scan was found to be the most sensitive investigation.

As a common ground for discussion, there are also divergent points of view. The understanding of GIST diagnosis and biology has improved significantly after the introduction of new imagistic methods and identification of new molecular markers. Yet, GISTs represent a peculiar type of tumor that challenges a positive and differential diagnosis with other mesenchymal tumors, both for the clinician and the pathologist.

\section{Acknowledgements}

Not applicable.

\section{Funding}

No funding was received.

\section{Availability of data and materials}

The datasets used and/or analyzed during the current study are available from the corresponding author on reasonable request.

\section{Authors' contributions}

MC, SE, VE, AB and ZC performed the histological examinations and IHC, and had major contributions in writing the manuscript. BS, VPC, VDC, LIS, DS, DP and CGS analyzed and interpreted the patient data. MC, BS and LIS searched the literature for similar research and articles and contributed to writing the manuscript. All authors read and approved the final manuscript.

\section{Ethics approval and consent to participate}

The study was conducted according to the World Medical Association Declaration of Helsinki, using a protocol approved 
by the local Bioethics Committee from 'Sf. Pantelimon' Emergency Clinical Hospital (Bucharest, Romania). All patients previously signed an informed written consent concerning hospitalization, treatment and a possible future publication of data.

\section{Patient consent for publication}

Not applicable.

\section{Competing interests}

The authors declare no conflict or competing interests.

\section{References}

1. Miettinen $\mathrm{M}$ and Lasota J: Gastrointestinal stromal tumors: Review on morphology, molecular pathology, prognosis, and differential diagnosis. Arch Pathol Lab Med 130: 1466-1478, 2006.

2. Foo WC, Liegl-Atzwanger B and Lazar AJ: Pathology of gastrointestinal stromal tumors. Clin Med Insights Pathol 5: 23-33, 2012.

3. Wada R, Arai H, Kure S, Peng WX and Naito Z: 'Wild type' GIST: Clinicopathological features and clinical practice. Patho Int 66: 431-437, 2016

4. Miettinen M, Killian JK, Wang ZF, Lasota J, Lau C, Jones L, Walker R,Pineda M,Zhu YJ,Kim SY, et al:Immunohistochemical loss of succinate dehydrogenase subunit A (SDHA) in gastrointestinal stromal tumors (GISTS) signals SDHA germline mutation. The Am J Surg Pathol 37: 234-240, 2013.

5. Gaal J, Stratakis CA, Carney JA, Ball ER, Korpershoek E, Lodish MB, Levy I, Xekouki P, van Nederveen HF, den Bakker MA, et al: SDHB immunohistochemistry: A useful tool in the diagnosis of carney-stratakis and Carney triad gastrointestinal stromal tumors. Mod Pathol 24: 147-151, 2011.

6. Tirumani SH, Tirumani H, Jagannathan JP, Shinagare AB, Hornick JL, George S, Wagner AJ and Ramaiya NH: MDCT features of succinate dehydrogenase (SDH)-deficient gastrointestinal stromal tumours. Br J Radiol 87: 20140476, 2014.

7. Reichardt P: The story of imatinib in GIST-a journey through the development of a targeted therapy. Oncol Res Treat 41: 472-477, 2018.

8. Zhang X, Bai L, Wang D, Huang X, Wei J, Zhang W, Zhang Z and Zhou J: Gastrointestinal stromal tumor risk classification: Spectral CT quantitative parameters. Abdom Radiol (NY) 44: 2329-2336, 2019.

9. Dei Tos AP, Hornick JL and Miettinen M: Gastrointestinal stromal tumour. In: WHO Classification of Tumours: Digestive system tumours. Fukayama M, Goldblum JR, Miettinen M and Lazar AJ (eds). 5th edition. World Health Organization (WHO), Geneva, pp439-443, 2019

10. Cavaliere D, Griseri G, Venturino E, Schirru A, Cosce U, Caristo I, Caliendo L, Pastorino A and Cavaliere P: Management of patients with gastrointestinal stromal tumors: Experience from an Italian group. Tumori 91: 467-471, 2005.

11. Lin SC, Huang MJ, Zeng CY, Wang TI, Liu ZL and Shiay RK: Clinical manifestations and prognostic factors in patients with gastrointestinal stromal tumors. World J Gastroenterol 9: 2809-2812, 2003.

12. Korodi AD, Furau C, Furau G, Dimitriu M, Socea B, Ada C, Botezatu D, Dumnici A, Totolici B, Barbu I, et al: The types of tumoral vessels associated to GISTs are conditioning the effectiveness of anti-vascular therapy with tyrosine kinase receptor inhibitors. Rev Chim (Bucharest) 70: 3250-3253, 2019.

13. Sorour MA, Kassem MI, Ghazal AE, El-Riwini MT and Nasr AA: Gastrointestinal stromal tumors (GIST) related emergencies. Int J Surg 12: 269-80, 2014.

14. Constantin VD, Socea B, Popa F, Carâp AC, Popescu G Vlădescu T, Ceauşu Z, Bertesteanu SVG and Ceauşu MC: A histopathological and immunohistochemical approach of surgical emergencies of GIST. An interdisciplinary study. Rom J Morphol Embryol 55 (Suppl 2): S619-S627, 2014.
15. Bouassida M, Chtourou MF, Chalbi E, Chebbi F, Hamzaoui L, Sassi S, Charfi L, Mighri MM, Touinsi H and Sassi A: Appendiceal GIST: Report of an exceptional case and review of the literature. Pan Afr Med J 15: 85, 2013.

16. Ajduk M, Mikulić D, Sebecić B, Gasparov S, Patrlj L, Erdelez L, Skopljanac A, Staresinić M, Desković S, Sosa T and Sitić S: Spontaneously ruptured gastrointestinal stromal tumor (GIST) of the jejunum mimicking acute appendicitis. Coll Antropol 28: 937-941, 2004

17. Giestas S, Almeida N, Martins R, Canhoto A, Oliveira P, Figueiredo P and Sofia C: Small bowel GIST: Clinical presentation as intussusception and obscure bleeding. GE Port J Gastroenterol 23: 279-281, 2016.

18. Miettinen M, Felisiak-Golabek A, Wang Z, Inaguma $S$ and Lasota J: GIST manifesting as a retroperitoneal tumor: Clinicopathologic immunohistochemical, and molecular genetic study of 112 cases. Am J Surg Pathol 41: 577-585, 2017.

19. Bratu OG, Marcu RD, Socea B, Neagu TP, Diaconu C, Scarneciu I, Turcu FL, Radavoi GD, Bratila E, Berceanu C and Spinu AD: Immunohistochemistry particularities of retroperitoneal tumors. Rev Chim (Bucharest) 69: 1813-1816, 2018.

20. Sista F, Pessia B, Abruzzese V, Cecilia EM, Schietroma M, Carlei F and Amicucci G: Twelve years of gastric GIST. A retrospective study of laparoscopic and open approach. Ann Ital Chir 86: 349-356, 2015.

21. Park JH, Kang BK, Lee HL, Yoon JH, Lee KN, Jun DW, Lee OY, Han DS, Yoon BC and Choi HS: Correlation between three-dimensional volume and malignant potential of gastrointestinal stromal tumors (GISTs). J Clin Med 9: 2763, 2020.

22. Parab TM, DeRogatis MJ, Boaz AM, Grasso SA, Issack PS, Duarte DA, Urayeneza O, Vahdat S, Qiao JH and Hinika GS: Gastrointestinal stromal tumors: A comprehensive review. J Gastrointest Oncol 10: 144-154, 2019.

23. Landi B: Gastrointestinal stromal tumors: Clinical features and diagnosis. Bull Acad Natl Med 196: 845-852, 2012 (In French).

24. von Mehren M and Joensuu H: Gastrointestinal stromal tumors. J Clin Oncol 36: 136-143, 2018.

25. Dimitrakopoulou-Strauss A, Ronellenfitsch U, Cheng C, Pan L, Sachpekidis C, Hohenberger P and Henzler T: Imaging therapy response of gastrointestinal stromal tumors (GIST) with FDG PET, CT and MRI: A systematic review. Clin Transl Imaging 5: 183-197, 2017.

26. Sanchez-Hidalgo JM, Duran-Martinez M, Molero-Payan R, Rufian-Peña S, Arjona-Sanchez A, Casado-Adam A, Cosano-Alvarez A and Briceño-Delgado J: Gastrointestinal stromal tumors: A multidisciplinary challenge. World J Gastroenterol 24: 1925-1941, 2018.

27. Lim KT and Tan KY: Current research and treatment for gastrointestinal stromal tumors. World J Gastroenterol 23: 4856-4866, 2017.

28. Landi B, Blay JY, Bonvalot S, Brasseur M, Coindre JM, Emile JF, Hautefeuille V, Honore C, Lartigau E, Mantion G, et al: Gastrointestinal stromal tumours (GISTs): French intergroup clinical practice guidelines for diagnosis, treatments and follow-up (SNFGE, FFCD, GERCOR, UNICANCER, SFCD, SFED, SFRO). Dig Liver Dis 51: 1223-1231, 2019.

29. Agaimy A and Wünsch PH: Gastrointestinal stromal tumours: A regular origin in the muscularis propria, but an extremely diverse gross presentation. A review of 200 cases to critically re-evaluate the concept of so-called extra-gastrointestinal stromal tumours. Langenbecks Arch Surg 391: 322-329, 2006.

30. Brcic I, Kashofer K, Skone D and Liegl-Atzwanger B: KIT mutation in a naïve succinate dehydrogenase deficient gastric GIST Genes Chromosomes Cancer 58: 798-803, 2019.

31. Gaopande VL, Joshi AR, Bhayekar PD and Khandeparkar SG: Clinicopathologic and immunohistochemical study of gastrointestinal stromal tumor (ten cases) and extragastrointestinal stromal tumor (six cases) with review of literature. J Curr Res Sci Med 2: 84-91, 2016.

32. Akahoshi K, Oya M, Koga T and Shiratsuchi Y: Current clinical management of gastrointestinal stromal tumor. World J Gastroenterol 24: 2806-2817, 2018.

33. Hirota S: Differential diagnosis of gastrointestinal stromal tumor by histopathology and immunohistochemistry. Transl Gastroenterol Hepatol 3: 27, 2018.

34. Lai J, Kresak JL, Cao D, Zhang D, Zhang S, Leon ME, Shenoy A, Liu W, Trevino J, Starostik P, et al: Gastric plexiform fibromyxoma: A great mimic of gastrointestinal stromal tumor (GIST) and diagnostic pitfalls. J Surg Res 239: 76-82, 2019. 
35. Alghamdi HM, Amr SS, Shawarby MA, Sheikh SS, Alsayyah AA Alamri AM, Ismail MH, Almarhabi A, Alrefaee MA and Ahmed MI: Gastrointestinal stromal tumors, A clinicopathological study. Saudi Med J 40: 126-130, 2019.

36. Kang HC, Menias CO, Gaballah AH, Shroff S, Taggart MW, Garg N and Elsayes KM: Beyond the GIST: Mesenchymal tumors of the stomach. Radiographics 33: 1673-1690, 2013.

37. Turner MS and Goldsmith JD: Best practices in diagnostic immunohistochemistry: Spindle cell neoplasms of the gastrointestinal tract. Arch Pathol Lab Med 133: 1370-1374, 2009.

38. Penel N, Chibon F and Salas S: Adult desmoid tumors: Biology, management and ongoing trials. Curr Opin Oncol 29: 268-274, 2017.

39. Lawrence B, Perez-Atayde A, Hibbard MK, Rubin BP, Cin PD, Pinkus JL, Pinkus GS, Xiao S, Yi ES, Fletcher CD and Fletcher JA: TPM3- ALK and TPM4-ALK oncogenes in inflammatory myofibroblastic tumors. Am J Pathol 157: 377-384, 2000.

40. Voltaggio L, Murray R, Lasota J and Miettinen M: Gastric schwannoma: A clinicopathologic study of 51 cases and critical review of the literature. Hum Pathol 43: 650-659, 2012.
41. Chmielecki J, Crago AM, Rosenberg M, O'Connor R, Walker SR, Ambrogio L, Auclair D, McKenna A, Heinrich MC, Frank DA and Meyerson M: Whole-exome sequencing identifies a recurrent NAB2-STAT6 fusion in solitary fibrous tumors. Nat Genet 45: 131-132, 2013.

42. Argani P, Aulmann S, Illei PB, Netto GJ, Ro J, Cho HY, Dogan S, Landanyi M, Martignoni G, Goldblum JR and Weiss SW: A distinctive subset of PE Comas harbors TFE3 gene fusions. Am J Surg Pathol 34: 1395-1406, 2010.

43. Joensuu H: Adjuvant treatment of GIST: Patient selection and treatment strategies. Nat Rev Clin Oncol 19: 351-358, 2012.

This work is licensed under a Creative Commons Attribution-NonCommercial-NoDerivatives 4.0 International (CC BY-NC-ND 4.0) License. 